Pacific Journal of Mathematic 


\title{
RATIO TESTS FOR CONVERGENCE OF SERIES
}

\author{
Ralph Palmer Agnew
}

1. Introduction. The following theorem was proved and used by Jehlke [2] to obtain elegant improvements of the classic tests of Gauss and Weierstrass for convergence of series of real and of complex terms.

THEOREM 1. If the terms of two series $\sum_{n=0}^{\infty} a_{n}$ and $\sum_{n=0}^{\infty} b_{n}$ are such that

$$
\frac{b_{n+1}}{b_{n}}=\frac{a_{n+1}}{a_{n}}\left(1+c_{n}\right) \quad(n=0,1, \cdots),
$$

where $\sum_{n=0}^{\infty} c_{n}$ is absolutely convergent, then the two series $\sum_{n=0}^{\infty} a_{n}$ and $\sum_{n=0}^{\infty} b_{n}$ are both convergent or both divergent.

It is the main object of this note to prove that Theorem 1 is a best possible theorem in that no hypothesis weaker than the hypothesis that $\sum_{n=0}^{\infty}\left|c_{n}\right|<\infty$ is sufficient to imply the conclusion of the theorem. The final result, Theorem 4 , is obtained from two preliminary theorems, The orems 2 and 3 , which seem to have independent interest.

2. Preliminary theorems. We first establish the following result.

THEOREM 2. Let $c_{n} \neq-1, n=0,1,2, \cdots$. In order that the sequence $\left\{c_{n}\right\}$ be such that $\sum_{n=0}^{\infty} b_{n}$ converges whenever (1) holds and $\sum_{n=0}^{\infty} a_{n}$ converges, it is necessary and sufficient that

$$
\sum_{n=1}^{\infty}\left|\left(1+c_{0}\right)\left(1+c_{1}\right) \cdots\left(1+c_{n-1}\right) c_{n}\right|<\infty .
$$

Proof. To prove Theorem 2, let (1) hold. Then

$$
\frac{b_{n+1}}{a_{n+1}}=\frac{b_{n}}{a_{n}}\left(1+c_{n}\right) \quad(n=0,1,2, \cdots),
$$

and hence 


$$
\frac{b_{n}}{a_{n}}=\frac{b_{0}}{a_{0}}\left(1+c_{0}\right)\left(1+c_{1}\right) \cdots\left(1+c_{n-1}\right) \quad(n=1,2, \cdots) .
$$

Let

$$
p_{n}=\frac{b_{0}}{a_{0}}\left(1+c_{0}\right)\left(1+c_{1}\right) \cdots\left(1+c_{n-1}\right) \quad(n=1,2, \cdots) .
$$

Then $b_{n}=p_{n} a_{n}$. But by a well-known theorem of Hadamard [1], $\sum_{n=0}^{\infty} p_{n} a_{n}$ converges whenever $\sum_{n=0}^{\infty} a_{n}$ converges if and only if $\sum_{n=0}^{\infty}\left|p_{n+1}-p_{n}\right|<\infty$. But

(5) implies that

$$
p_{n+1}-p_{n}=\frac{b_{0}}{a_{0}}\left(1+c_{0}\right)\left(1+c_{1}\right) \cdots\left(1+c_{n-1}\right) c_{n},
$$

and the conclusion of Theorem 2 follows.

THE OREM 3. Let $c_{n} \neq-1, n=0,1,2, \cdots$. In order that the sequence $\left\{c_{n}\right\}$ be such that $\sum_{n=0}^{\infty} a_{n}$ converges whenever (1) holds and $\sum_{n=0}^{\infty} b_{n}$ converges, it is necessary and sufficient that

$$
\sum_{n=1}^{\infty}\left|\frac{1}{1+c_{0}} \frac{1}{1+c_{1}} \cdots \frac{1}{1+c_{n-1}} \frac{c_{n}}{1+c_{n}}\right|<\infty .
$$

Proof. Theorem 3 may be proved by revising the proof of Theorem 2 to use the relations

$$
\frac{a_{n+1}}{a_{n}}=\frac{b_{n+1}}{b_{n}} \frac{1}{1+c_{n}} \quad(n=0,1,2, \cdots)
$$

instead of (1) or, which amounts to the same thing, replacing $1+c_{k}$ by $1 /\left(1+c_{k}^{\prime}\right)$ in (2) and then removing the primes.

3. Theorem. Our main result is the following.

THEOREM 4. Let $c_{n} \neq-1, n=0,1,2, \cdots$. In order that this sequence be such that the two series $\sum_{n=0}^{\infty} a_{n}$ and $\sum_{n=0}^{\infty} b_{n}$ are both convergent or both divergent whenever (1) holds, it is necessary and sufficient that $\sum_{n=0}^{\infty}\left|c_{n}\right|<\infty$.

Proof. To prove necessity, suppose $\sum_{n=0}^{\infty} a_{n}$ and $\sum_{n=0}^{\infty} b_{n}$ are both convergent or both divergent whenever (1) holds. Then, by The ore ms 2 and 3, both (2) and (7) 
hold. Denoting the $n$th terms of the series in (2) and (7) by $u_{n}$ and $v_{n}$, we see that, as $n \longrightarrow \infty$, we have $u_{n} \longrightarrow 0$ and $v_{n} \longrightarrow 0$ and hence

$$
u_{n} v_{n}=\frac{c_{n}^{2}}{1+c_{n}} \longrightarrow 0
$$

This implies that $c_{n} \longrightarrow 0$ and hence that $\left|1 /\left(1+c_{n}\right)\right|>1 / 2$ for $n$ sufficiently great. This and (7) imply that

$$
\sum_{n=1}^{\infty}\left|\frac{1}{1+c_{0}} \frac{1}{1+c_{1}} \cdots \frac{1}{1+c_{n-1}} c_{n}\right|<\infty .
$$

If we let $x_{n}=\left|\left(1+c_{0}\right)\left(1+c_{1}\right) \cdots\left(1+c_{n-1}\right)\right|$, then (2) and (10) imply that

$$
\sum_{n=1}^{\infty}\left(x_{n}+x_{n}^{-1}\right)\left|c_{n}\right|<\infty
$$

But the mere fact that $x_{n}>0$ implies that $\left(x_{n}+x_{n}^{-1}\right) \geq 2$, and it follows that $\sum_{n=0}^{\infty}\left|c_{n}\right|<\infty$. This proves necessity. To prove sufficiency, suppose that $\sum_{n=0}^{\infty}\left|c_{n}\right|<\infty$. Then the infinite product $\Pi\left(1+c_{k}\right)$ converges to a number not zero, and this means that each of $\left(1+c_{0}\right)\left(1+c_{1}\right) \cdots\left(1+c_{n-1}\right)$ and $\left[\left(1+c_{0}\right)\right.$ $\left.\left(1+c_{1}\right) \cdots\left(1+c_{n}\right)\right]^{-1}$ converges to a number not zero. This and $\Sigma_{n=0}^{\infty}\left|c_{n}\right|$ $<\infty$ imply (2) and (7). Therefore Theorems 2 and 3 imply that $\sum_{n=0}^{\infty} a_{n}$ and $\sum_{n=0}^{\infty} b_{n}$ are both convergent or both divergent. This completes the proof of Theorem 4 .

\section{REFERENCES}

1. J. Hadamard, Deux théorèmes d'Abel sur la convergence des series, Acta. Math., 27 (1903), 177-183.

2. H. Jehlke, Eine Bemerkung zum Konvergenzkriterium von Weierstrass, Mathematische Zeitschrift, 52 (1949), 60-61.

CorNell UNIVERSity 



\title{
EDITORS
}

\author{
HERBERT BUSEMANN \\ University of Southern California \\ Los Angeles 7, California
}

R. M. RoBINSON

University of California

Berkeley 4, California

E. F. BECKENBACH, Managing Editor

University of California

Los Angeles 24, California

ASSOCIATE EDITORS
R. P. DILWORTH
P. R. HALMOS
BQRGE JESSEN
J. J. STOKER
HERBERT FEDERER
HEINZ HOPF
PAUL LÉVY
E. G. STRAUS
MARSHALL HALL
R. D. JAMES
GEORGE PÓLYA
KÔSAKU YOSIDA

\section{SPONSORS}

UNIVERSITY OF BRITISH COLUMBIA

CALIFORNIA INSTITUTE OF TECHNOLOGY UNIVERSITY OF CALIFORNIA, BERKELEY

UNIVERSITY OF CALIFORNIA, DAVIS

UNIVERSITY OF CALIFORNIA, LOS ANGELES

UNIVERSITY OF CALIFORNIA, SANTA BARBARA

OREGON STATE COLLEGE

UNIVERSITY OF OREGON
UNIVERSITY OF SOUTHERN CALIFORNIA STANFORD UNIVERSITY

WASHINGTON STATE COLLEGE

UNIVERSITY OF WASHINGTON

AMERICAN MATHEMATICAL SOCIETY NATIONAL BUREAU OF STANDARDS, INSTITUTE FOR NUMERICAL ANALYSIS

\section{Vari-Type Composition by \\ Cecile Leonard \\ Ruth Stafford}

With the cooperation of

E. F. Beckenbach

E. G. Straus

Printed in the United States of America by

Edwards Brothers, Inc., Ann Arbor, Michigan

UNIVERSITY OF CALIFORNIA PRESS - BERKELEY AND LOS ANGELES COPYRIGHT 1951 BY PACIFIC JOURNAL OF MATHEMATICS 


\section{Pacific Journal of Mathematics}

\section{Vol. 1, No. $1 \quad$ November, 1951}

Ralph Palmer Agnew, Ratio tests for convergence of series............. 1

Richard Arens and James Dugundji, Topologies for function spaces....... 5

B. Arnold, Distributive lattices with a third operation defined ........... 33

R. Bing, Concerning hereditarily indecomposable continua ........... 43

David Dekker, Generalizations of hypergeodesics ............... 53

A. Dvoretzky, A. Wald and J. Wolfowitz, Relations among certain ranges of vector measures.................................... 59

Paul Erdős, F. Herzog and G. Pirani, Schlicht Taylor series whose convergence on the unit circle is uniform but not absolute .......... 75

Whilhelm Fischer, On Dedekind's function $\eta(\tau) \ldots \ldots \ldots \ldots \ldots \ldots . \ldots 3$

Werner Leutert, The heavy sphere supported by a concentrated force ...... 97

Ivan Niven and H. Zuckerman, On the definition of normal numbers ...... 103

L. Paige, Complete mappings of finite groups .................. 111

Otto Szász, On a Tauberian theorem for Abel summability ............. 117

Olga Taussky, Classes of matrices and quadratic fields ............. 127

F. Tricomi and A. Erdélyi, The asymptotic expansion of a ratio of gamma functions .................................... 133

Hassler Whitney, On totally differentiable and smooth functions ......... 143 